\title{
Estimation of Micromobility at the end of Circuits in Treatment in Ilizarov of Diseases and Fracturing of the Tibia and Shoulder Bones
}

\author{
VA Schurov* \\ Federal State Budgetary Institution Russian Research Center "Restorative Traumatology and Orthopedics", Russia
}

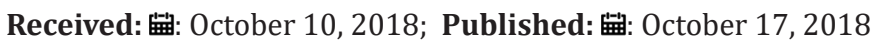

*Corresponding author: VA Schurov, Federal State Budgetary Institution Russian Research Center "Restorative Traumatology and Orthopedics" named after GA Ilizarov, Russia

\section{Introduction}

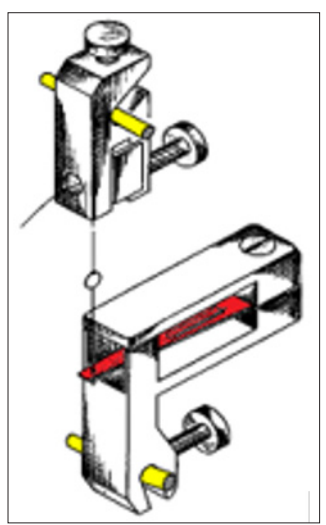

Figure 1: Strain gauge and clamp to determine changes in the distance between the spokes of the Ilizarov apparatus.

A strain gauge device has been developed that allows determining the change in the distance between the spokes of an external fixation device emerging from opposing bone fragments when the axial load on the injured limb is gradually increased in steps of $10 \mathrm{kgf}$ (Figure 1). At the same time, the control of stiffness of fixation of fragments can be carried out throughout the period of fixation of bone fragments. Strain gauge and clamp to determine changes in the distance between the spokes of the Ilizarov apparatus. Surveyed 2 groups of patients with closed diaphyseal fractures of the bones of the leg, treated according to the method of AI Ilizarov. Patients of the $1^{\text {st }}$ group (156 patients aged from 17 to 63 years old were treated in the hospital of the clinic. The $2^{\text {nd }}$ group included their peers (64 people, 20-76 years old) with the same pathology, who passed after a period of inpatient treatment for 10-14 days further treatment on an outpatient basis. Patients of the 3rd group (38 patients) who received outpatient treatment had diaphyseal fractures of the humerus. In patients of the 4 th group (25 patients aged from 3 to 36 years), Ilizarov elongation of a lagging tibia was averaged by $4.5 \pm 0.5 \mathrm{~cm}$.

\section{Results}

In patients of the 1st group, the duration of the fixation period was $59 \pm 1.4$ days, the cross-sectional area of the periosteal corns on the day of fixation was $45 \pm 15 \mathrm{~mm}^{2}$. The transfer of patients of the $2^{\text {nd }}$ group led to a temporary increase in the micromotion of bone fragments (Figure 2). The duration of the fixation period of bone fragments was $66 \%$ longer $(\mathrm{p} \leq 0.01)$. The cross-sectional area of the periosteal corn reached $213 \pm 25 \mathrm{~mm}^{2}$. When treating patients with fractures of the humerus, it was revealed that the tolerance of axial load in them is 3 times less, the micromobility of the bone fragments is higher and after switching to treatment in the outpatient setting, there is no increase in the micromotion of fragments (Figure 3). The duration of the fixation period reached an average of $82 \pm 3.4$ days. The average size of periosteal callus was $153 \pm 16 \mathrm{~cm}^{2}$. The ratio of the corns of the humerus and tibial bones is comparable with the ratio of the nominal diameters of these bones ( $25 \pm 0.8$ and $18 \pm 0.8 \mathrm{~mm}$ ). With operative lengthening of the tibia that was lagging behind in growth, the micro-mobility index of the ends of the fragments was relatively less than in the treatment of patients with fractures, depended on the magnitude of 
the limb lengthening and steadily decreased after the termination of distraction (Figure 4).

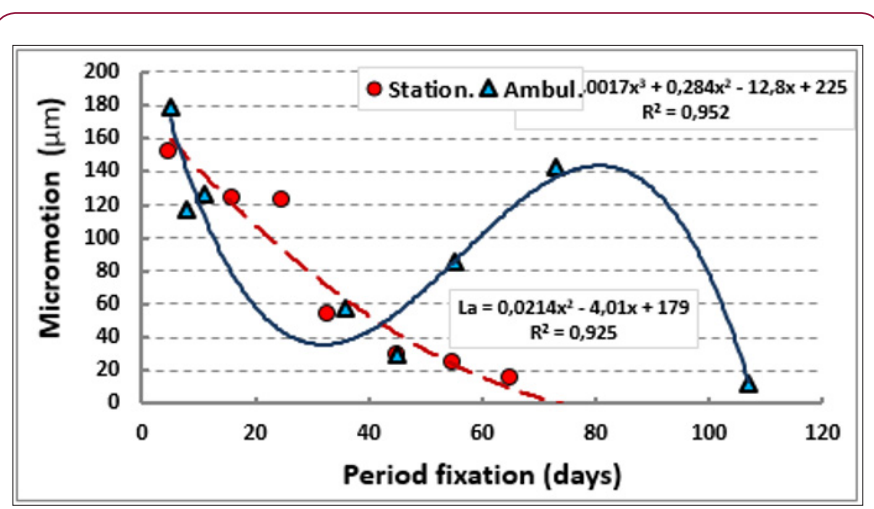

Figure 2: Dynamics of micromotion of bone fragments of the tibia in the treatment of patients with closed leg injuries in inpatient and outpatient settings.

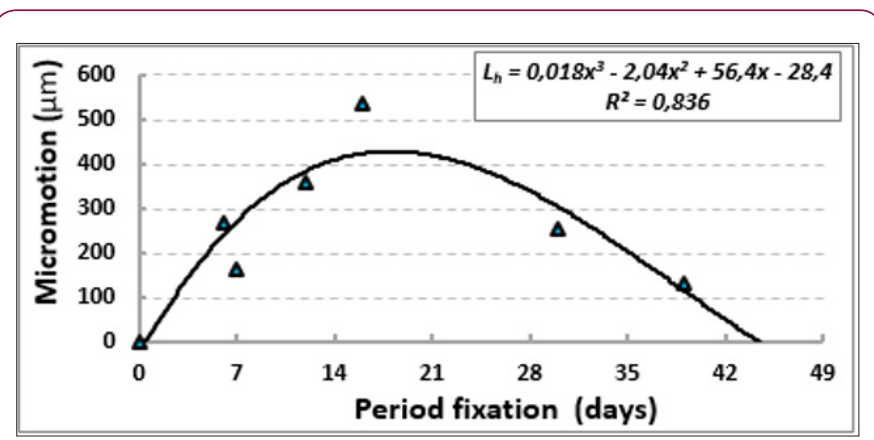

Figure 3: Dynamics of micromotion of bone fragments in the treatment of patients with fractures of the shoulder.

ISSN: 2574-1241

DOI: 10.26717/BJSTR.2018.10.001911

VA Schurov. Biomed J Sci \& Tech Res

(c) (i) This work is licensed under Creative

Submission Link: https://biomedres.us/submit-manuscript.php

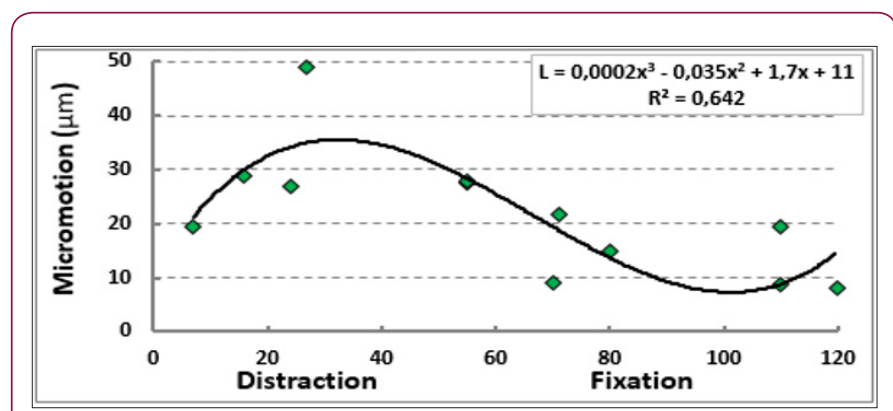

Figure 4: Dynamics of micromotion of bone fragments during operative lengthening of the leg.

\section{Conclusion}

The method of measuring the micromotion of bone fragments allows to obtain valuable information about the condition of callus in the process of treating fractures of the bones of the upper and lower extremities and in correcting their longitudinal dimensions according to the Ilizarov method.

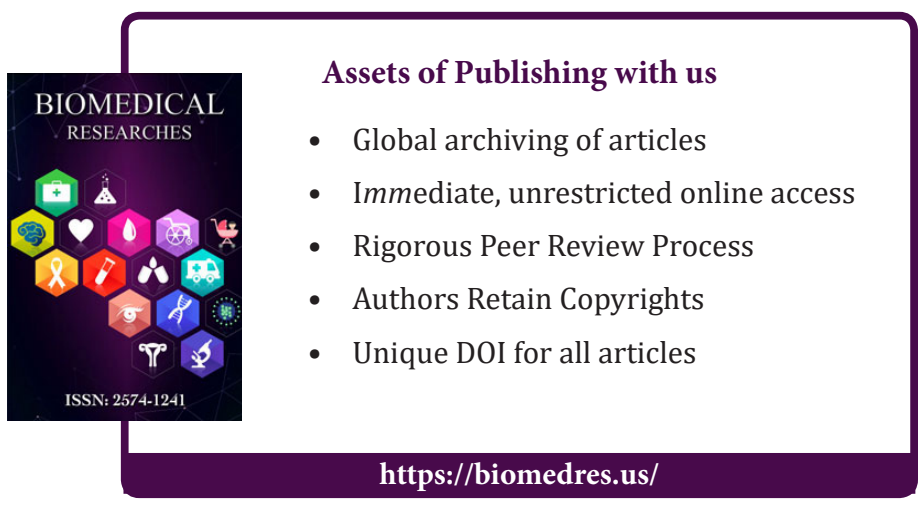

Cite this article: VA Schurov. Estimation of Micromobility at the end of Circuits in Treatment in Ilizarov of Diseases and Fracturing of the Tibia and Shoulder Bones. Biomed J Sci\&Tech Res 10(2)-2018. BJSTR. MS.ID.001911. DOI: 10.26717/ BJSTR.2018.10.001911. 